\title{
Prevalence of spondyloarthropathies in France: 2001
}

\author{
A Saraux, F Guillemin, P Guggenbuhl, C H Roux, P Fardellone, E Le Bihan, \\ A Cantagrel, I Chary-Valckenaere, L Euller-Ziegler, R-M Flipo, R Juvin, J-M Behier, \\ B Fautrel, C Masson, J Coste
}

See end of article for authors' affiliations

Correspondence to:

Professor A Saraux, Rheumatology Unit, la Cavale Blanche Hospital, Brest Teaching Hospital, BP 814, F 29609 Brest-

Cedex, France; Alain.Saraux@ univ-brest.fr

Accepted 14 March 2005 Published Online First 7 April 2005

Objective: To estimate the prevalence of spondyloarthropathies ( $\mathrm{SpAs}$ ) in France in a multiregional representative sample in the year 2001.

Methods: A two stage random sample was constituted in seven areas from the national telephone directory and the next birthday method in each household. Interviewers were patient-members of self help groups trained to administer telephone surveys using a validated questionnaire for detecting inflammatory joint disease. Quality of data collection was controlled periodically. SpA was confirmed by the patient's rheumatologist or by clinical examination. Prevalence estimates after probability sampling correction were standardised for age and sex (1999 national census).

Results: Among the 15219 anonymous telephone numbers selected, 3.6\% were places of work or secondary residences and were excluded. The phone interview participation rate ranged across regions from 55.1 to $69.9 \%$. 3554 men and 5841 women were included in the study. Twenty nine cases of SpA were confirmed. All but one fulfilled ESSG criteria. Mean age was 47 years (range 21-78). The overall prevalence standardised for age and sex was $0.30 \%$ (95\% confidence interval (CI) 0.17 to 0.46 ). Prevalence was similar in women $(0.29 \%(95 \% \mathrm{Cl} 0.14$ to 0.49$))$ and men $(0.31 \%(95 \% \mathrm{Cl} 0.12$ to 0.60$))$. Geographical analysis by department clustering found no significant differences. The prevalence of SpA was as high as that of rheumatoid arthritis.

Conclusion: Prevalence of SpA in France was $0.30 \%$ in 2001, with no difference between women and men. Ankylosing spondylitis and psoriatic arthritis were the most common $\mathrm{SpA}$ subsets.

$\mathrm{T}$ he arthritides classified in the spondyloarthropathy (SpA) group share a number of axial manifestations (sacroiliitis and spinal involvement), peripheral musculoskeletal abnormalities (arthritis, dactylitis, and enthesopathy), extra-articular symptoms (uveitis, inflammatory bowel disease, and psoriasis), and genetic characteristics (class I antigen HLAB27 or familial clustering, or both). The SpAs include ankylosing spondylitis, psoriatic arthritis, reactive arthritis, enteropathic arthropathy, and undifferentiated SpA. ${ }^{1}$

The concept of SpA is useful in several ways. Firstly, it may help clinicians to collect the group of articular, extraarticular, and genetic features needed to establish the diagnosis, predict outcomes, and select treatments. Secondly, it may help to classify patients who have overlap forms or undifferentiated SpA. Thirdly, the concept of SpA has led to the development of validated classification criteria (European Spondylarthropathy Study Group (ESSG) criteria and Amor criteria), ${ }^{12}$ which considerably facilitate epidemiological studies.

Rheumatoid arthritis (RA) and SpA are the most common inflammatory joint diseases in adults and generate a huge burden of work disability, functional impairment, and handicap.

Among the SpAs, ankylosing spondylitis has received the lion's share of research attention over the past three decades, and few epidemiological studies have examined SpAs in general. The estimated prevalence of SpA is about $0.25 \%$, except in Africa. ${ }^{3-13}$

A pilot telephone survey was performed in Brittany, France. ${ }^{14}$ Patients with suspected SpA were detected by patient-interviewers using a standardised detection questionnaire. Diagnoses were confirmed by visits to rheumatologists. Of the 2873 people screened, 672 reported symptoms consistent with RA or SpA but no diagnosis; among them, only two patients had RA or SpA. In contrast, 28 of 30 patients in whom RA or SpA was confirmed reported their diagnosis during the screening interview. The results suggested a similar prevalence for RA and SpA, with no marked male predominance for SpA. The pilot study also established that detection of inflammatory joint disease by phone interview was feasible and that the diagnoses reported by individual subjects provided reliable estimates of prevalence. We concluded that this low cost method might be useful for comparing countries or regions.

The epidemiology committee of the French Society of Rheumatology then conducted a study to test a short questionnaire suitable for use in telephone surveys conducted by patient-interviewers. ${ }^{15}{ }^{16}$ In this study, called Epirhuml, 230 patients with RA, 175 patients with SpA, and 195 controls were examined by hospital based rheumatologists. Patients from self help groups and social organisations were trained by a polling company and then used the questionnaire to conduct standard telephone interviews in which respondents were asked about diagnoses and ESSG criteria. ${ }^{1}$ In the SpA-control comparison, self reported diagnosis yielded the best performance characteristics (sensitivity $=0.85$; specificity $=0.96$ ). The questionnaire performed satisfactorily when administered over the phone by patientinterviewers.

Abbreviations: $\mathrm{Cl}$, confidence interval; ESSG, European Spondylarthropathy Study Group; RA, rheumatoid arthritis; SpA, spondyloarthropathy 
First step

Second step
Random selection of households' telephone numbers ( $n=15$ 219)

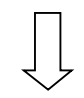

Exclusion of secondary residences and places of work

Random selection of adults in households by next birthday method $(n=9395)$

Case detection by patient-interviewers using a validated questionnaire (screening 1)

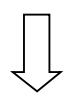

Third step

Patients with suspected SpA were called by rheumatologists (screening 2) $(n=85)$

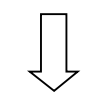

Fourth step

Patient's rheumatologist contacted (confirmation 1) ( $n=34)$

Patients with no rheumatologist were invited to investigation centre (confirmation 2) $(n=5)$<smiles>C1CCC1</smiles>

SpA confirmed $(n=29)$

Figure 1 Process of sampling (random selection of telephone numbers and random selection of one adult from each household) and case ascertainment (case detection and case confirmation).

Here, we report our findings from a subsequent study, Epirhum2. The objectives were to estimate the prevalence of SpA in France, to look for differences in prevalence across regions, and to compare the prevalence of RA and SpA in men and women.

\section{METHOD}

Figure 1 outlines the methods used.

A nationwide multistage sample survey was conducted in 20 counties distributed across France. The survey was managed by seven study centres. Data were collected using a validated telephone survey questionnaire administered by patient-interviewers, ${ }^{16}$ who were recruited from self help groups and trained by employees of a polling company. The counties were selected to ensure representation of the various population groups living in France. Areas of high urban concentration with high rates of migration (for example, Paris) were excluded from the survey.

The first stage of sampling was a random selection of numbers from the public telephone list. Places of business and institutions were excluded before dialling and secondary places of residence after dialling.

The second stage of sampling was selection of the adult (older than 18 years) whose birthday was the first to fall after the interview. ${ }^{17}$ This adult was then invited to participate in the survey. There were no exclusion criteria. The phone survey served to detect possible cases of SpA. The 33 items in the questionnaire included the following two questions: "Do you have a present or past history of pain in your joints?" and "Do you have a present or past history of pain in your neck, back, or buttocks?" Respondents who answered "yes" to one or both of these questions were asked "What diagnosis were you given for the pain?" Suspected SpA was defined as any of the following answers: "spondyloarthropathy", "spondylitis", "ankylosing spondylitis", "pelvispondylitis", "psoriatic arthritis", "psoriasis and arthritis", "reactive arthritis", "Reiter's syndrome", "joint disease related to bowel disease", "joint disease related to Crohn's disease", or "joint disease related to ulcerative colitis". Respondents with suspected SpA received a phone call from a rheumatologist who used a standardised list of symptoms and signs to evaluate the likelihood of SpA. When the results did not rule out SpA, the patient's rheumatologist was contacted and asked for the diagnosis. No further investigations and tests were obtained, except in those patients with no definite diagnosis, who were either re-evaluated by their own rheumatologist or invited to the closest study centre for an evaluation. Patients who had no rheumatologist were offered a thorough evaluation at the closest study centre, where the rheumatologist performed a physical examination and ordered any investigations deemed appropriate. For each patient, the rheumatologist's diagnosis was taken as the "gold standard".

The sample size was calculated assuming that the prevalence of SpA would be as low as $0.3 \%$ in some regions and that the refusal rate would be about $20 \%$. Assuming a Poisson distribution, contacting 4000 people by phone would yield a confidence interval of $0.14 \%$ to $0.54 \%$ around the $0.3 \%$ point estimate.

When computing estimated prevalences, we took into account both the proportion of the county population that was in the county sample and the size of the households in each county sample. Standardised estimates were calculated based on the age and sex distribution in the source population as determined by the last national census (1999, INSEE http://insee.fr/, accessed 11 July 2005). The 95\% confidence intervals (95\% CIs) were calculated using an approximation based on a $\gamma$ distribution of the weighted sum of independent random Poisson variables, which provides a conservative confidence interval estimate when the standard population is not proportional to the study population. ${ }^{5}$ Statistical tests were run using Sudaan software (SAS).

\section{RESULTS}

The seven study centres recruited 110 trained interviewers, and 23 rheumatologists helped to confirm the diagnosis. Among the 15219 selected anonymous telephone numbers, 
$3.6 \%$ were places of business or secondary residences. The household participation rate varied across regions from $55.1 \%$ to $69.9 \%$ (mean $64.7 \%$ ); "household participation" was defined as administration of the survey questionnaire to the adult in the household selected by the next birthday method. Households were selected from a list of telephone numbers classified by county, and therefore no other information was available for non-respondents. Among respondents identified as possible $\mathrm{SpA}$ cases, none refused the confirmation process. The age and sex distributions of the source and survey populations are reported in the companion paper. ${ }^{18}$

Twenty nine cases of SpA were confirmed in 11 men and 18 women with a mean age of 47 years (range 21-78). Table 1 reports the ESSG criteria. A single patient failed to meet ESSG criteria; however, she had two major criteria and was given a diagnosis of SpA by the study centre rheumatologist. Diagnoses established independently from classification criteria were as follows: ankylosing spondylitis, 14 patients; psoriatic arthritis, 12 patients; and others, 4 patients (one patient was given two diagnoses, ankylosing spondylitis and psoriatic arthritis). The American College of Rheumatology functional class was available for 23 patients; of whom, 7, 5, 6 , and 5 were stages I, II, III, and IV, respectively. Of the 18 patients for whom the erythrocyte sedimentation rate at the last visit was available, six had a value of $30 \mathrm{~mm} / \mathrm{lst} \mathrm{h}$ or more.

Of the 29 patients, 16 completed a self questionnaire. Their number of years of schooling was $\leqslant 5$ in two patients, $6-12$ in nine patients, and $>12$ in five patients. Of the 15 patients who answered the item on occupation, eight were employed, six retired, and one unemployed.

The overall prevalence standardised for age and sex was $0.30 \%$ (95\% CI 0.17 to 0.46 ]. The prevalence was similar in women $(0.29 \%$; $95 \%$ CI 0.14 to 0.49$)$ and men $(0.31 \%$; $95 \%$ CI
Table 2 Prevalence of spondyloarthropathy across age groups

\begin{tabular}{lll}
\hline Age class & Rate (\%) & $95 \% \mathrm{Cl}$ \\
\hline $18-24$ & 0.14 & 0.014 to 0.42 \\
$25-34$ & 0.28 & 0.07 to 0.64 \\
$35-44$ & 0.31 & 0.09 to 0.65 \\
$45-54$ & 0.37 & 0.05 to 1.00 \\
$55-64$ & 0.45 & 0.08 to 1.16 \\
$65-74$ & 0.40 & 0.07 to 1.01 \\
$75-84$ & 0.09 & 0.002 to 0.33 \\
$85+$ & 0.00 &. \\
\hline
\end{tabular}

0.12 to 0.60 ). Prevalences were $0.19 \%$ (95\% CI 0.08 to 0.35 ) for psoriatic arthritis and $0.08 \%$ (95\% CI $0.03 \%$ to $0.15 \%$ ) for ankylosing spondylitis. Given the sensitivity (0.85) of the screening questionnaire ${ }^{12}$ and the specificity error, controlled for by confirmation stage, the true prevalence of SpA in France may be as high as $0.4 \%\left(\mathrm{p}=\mathrm{p}_{\text {observed }} /\right.$ sensitivity $)$. Table 2 shows the age distribution of the prevalence standardised for age and sex. Prevalence increased slightly from 18 to 70 years of age.

Prevalence ranged across regions from $0 \%$ to $0.8 \%$; no significant differences were found according to geographical location, even when we looked at regions in groups such as north and south, east and west, north east and south west, or north west and south east (data not shown).

\section{DISCUSSION}

As far as we know, this study is the first estimate of the prevalence of SpA in France. The reproducible and relatively

Table 1 Diagnosis and ESSG criteria in 29 patients with spondyloarthropathy

\begin{tabular}{|c|c|c|c|c|c|c|c|c|}
\hline Patient & $\begin{array}{l}\text { Age } \\
\text { (years) }\end{array}$ & Sex & Diagnosis & $\begin{array}{l}\text { Date of } \\
\text { diagnosis }\end{array}$ & $\begin{array}{l}\text { ESSG } \\
\text { synovitis * }\end{array}$ & $\begin{array}{l}\text { ESSG spinal } \\
\text { pain } \dagger\end{array}$ & $\begin{array}{l}\text { ESSG } \\
\text { criterion } \ddagger\end{array}$ & Other ESSG criteria§ \\
\hline 1 & 51 & $\mathrm{~F}$ & AS & 1994 & + & + & + & Enthesitis, buttock pain, sacroiliitis \\
\hline 2 & 50 & $\mathrm{~F}$ & Undifferentiated & 1984 & + & + & + & Psoriasis, enthesitis, buttock pain \\
\hline 3 & 31 & $\mathrm{~F}$ & PsA & 1997 & - & + & + & Psoriasis, buttock pain, sacroiliitis \\
\hline 4 & 26 & $\mathrm{~F}$ & Undifferentiated & $?$ & - & + & + & Family history \\
\hline 5 & 67 & $M$ & AS & 1992 & - & + & + & Enthesitis, buttock pain, sacroiliitis \\
\hline 6 & 45 & $\mathrm{~F}$ & AS & 1990 & - & + & + & Family history, enthesitis, buttock pain, sacroiliitis \\
\hline 7 & 33 & $M$ & AS & 1990 & - & + & + & Family history, enthesitis, buttock pain, sacroiliitis \\
\hline 8 & 43 & $M$ & PsA & 1991 & - & + & + & Psoriasis, enthesitis, buttock pain, \\
\hline 9 & 21 & $M$ & Undifferentiated & $?$ & + & + & + & Family history, psoriasis, infection \\
\hline 10 & 50 & M & AS & 1985 & + & + & + & Family history, sacroiliitis \\
\hline 11 & 70 & $\mathrm{~F}$ & $A S$ and $P_{s} A$ & 1992 & + & - & + & Family history, psoriasis, infection, enthesitis, sacroiliitis \\
\hline 12 & 78 & $\mathrm{~F}$ & PsA & 1970 & + & + & + & Family history, psoriasis, buttock pain, sacroiliitis \\
\hline 13 & 23 & $\mathrm{~F}$ & PsA & 1992 & - & + & + & Family history, psoriasis \\
\hline 14 & 43 & $\mathrm{~F}$ & PsA & 1986 & - & + & + & Psoriasis, sacroiliitis \\
\hline 15 & 60 & $M$ & PsA & 1967 & + & + & + & Buttock pain, sacroiliitis \\
\hline 16 & 52 & $\mathrm{~F}$ & Undifferentiated & 1990 & + & + & - & \\
\hline 17 & 66 & $\mathrm{~F}$ & AS & 1979 & - & + & + & Family history, buttock pain, sacroiliitis \\
\hline 18 & 36 & $M$ & AS & 1988 & + & + & + & Buttock pain, sacroiliitis \\
\hline 19 & 66 & $\mathrm{~F}$ & AS & 1972 & - & + & + & Enthesitis, buttock pain, sacroiliitis \\
\hline 20 & 31 & $\mathrm{~F}$ & AS & 1997 & - & + & + & Family history, buttock pain, sacroiliitis \\
\hline 21 & 40 & $\mathrm{~F}$ & PsA & 1991 & - & + & + & Psoriasis, buttock pain \\
\hline 22 & 27 & $M$ & AS & 1990 & + & + & + & Enthesitis, buttock pain, sacroiliitis \\
\hline 23 & 39 & $M$ & AS & 1992 & - & + & + & Enthesitis, buttock pain, sacroiliitis \\
\hline 24 & 68 & $\mathrm{~F}$ & AS & 1988 & - & + & + & Buttock pain \\
\hline 25 & 32 & $\mathrm{~F}$ & AS & 1995 & - & + & + & Family history, buttock pain \\
\hline 26 & 57 & $\mathrm{~F}$ & PsA & 1989 & + & + & + & Psoriasis, buttock pain \\
\hline 27 & 69 & $M$ & PsA & 1960 & + & - & + & Psoriasis, enthesitis, IBD \\
\hline 28 & 53 & $M$ & PsA & 1975 & + & - & + & Family history, psoriasis \\
\hline 29 & 63 & $\mathrm{~F}$ & PsA & 1995 & + & - & + & Family history, psoriasis, infection \\
\hline
\end{tabular}


inexpensive method used in our study could be used to assess trends over time.

The worldwide epidemiology of SpA is generating interest for two main reasons: epidemiological data may help to discriminate between the role of environmental and genetic factors in the pathogenesis of the SpAs, and new drugs have been introduced recently. These new drugs, which include anti-tumour necrosis factor agents, are highly effective but also costly. Owing to this high cost, criteria for their use should be determined to ensure optimal cost efficacy, and the number of patients who should receive anti-tumour necrosis factor treatment needs to be estimated. Evaluating the prevalence of SpAs is a first step towards achieving these two goals.

Previous reports suggest that telephone surveys may be a viable alternative to costly face to face surveys in cross sectional studies of the general population, although biases may arise from telephone coverage variability, telephone sampling techniques, response differences between telephone and face to face interviews, and response rates. ${ }^{19-25}$

One possible source of bias is the increasing use of mobile phones, most notably by young people; mobile phone numbers are not included in telephone lists. However, most homes in France still have a fixed line. In France, more than 97\% of homes had a landline phone in 2000 (France-Telecom, personal communication). In our study, another possible source of bias was the exclusion of institutions, which may have contributed to the low prevalence in people older than 75 years of age.

Agreement between questionnaire data and medical records is considered good in prevalence studies for chronic diseases that have a clear diagnosis and are easily explained to the patient. However, two factors may distort information from self questionnaires: patients may misunderstand their diagnosis, and they may be unwilling to report symptoms or diagnoses to unknown interviewers who contact them over the phone. To minimise this last factor, the study can be announced in local newspapers and on radio stations. In addition to these two factors, self reported criteria may lack specificity. In a preliminary study (Epirhuml), a self reported diagnosis was clearly the best criterion for detecting SpA by phone interview in France. Nevertheless, to improve specificity in the present study, we obtained confirmation of each diagnosis of SpA by a rheumatologist.

The response rate was satisfactory $(64.7 \%$ of the homes called). Of the 29 patients with suspected SpA based on the phone interview, 27 allowed us to contact their rheumatologist and 23 answered a mailed questionnaire.

Ankylosing spondylitis and psoriatic arthritis were the most common patterns of SpA diagnosed by rheumatologists in our study. These diagnoses were not based on classification criteria. A number of overlap forms were found, confirming that some patients whose manifestations do not allow a specific diagnosis can be captured in epidemiological studies that use SpA as a general concept. For example, on the one hand, for a number of patients with psoriasis, the rheumatologists gave a diagnosis of undifferentiated $\mathrm{SpA}$ or ankylosing spondylitis, and on the other, several patients without psoriasis had a diagnosis of psoriatic arthritis.

The prevalence of severe ankylosing spondylitis has been estimated at $0.0047 \%$ in France based on cases reported to the universal health insurance system. ${ }^{4}$ The prevalence of SpA in our study was $0.30 \%$, in keeping with data obtained in America, ${ }^{7}$ China, ${ }^{8}$ or the Scottish Highlands, ${ }^{5}$ which relied on detection in the general population or through general practitioners. Lower prevalences were found in Greece and Japan in studies that identified only patients referred to hospitals or rheumatologists. ${ }^{10-12}$ On the other hand, the prevalence of SpA was about $1.9 \%$ in Berlin in a study of 348 blood donors who were routinely subjected to a physical examination and to magnetic resonance imaging of the sacroiliac joints. These discrepancies underline the considerable impact of methodological factors. Population based studies are probably more relevant than studies of patients referred to hospitals or rheumatologists. Nevertheless, the best method for screening and case ascertainment remains a matter of debate. Our method identifies patients who have a diagnosis and has been validated for this purpose; however, it may miss cases of mild undiagnosed SpA. A single patient received a diagnosis of SpA in conjunction with the study, although the diagnosis had been considered previously. Thus, our results reflect the prevalence of suspected or diagnosed $\mathrm{SpA}$ in the general population rather than the true prevalence of SpA.

The prevalence of SpA was similar in men and women ( $0.31 \%$ (95\% CI 0.12 to 0.60$)$ in men and $0.29 \%$ (95\% CI 0.14 to 0.49 ) in women) in our study. SpA is usually reported as being more common in men. Our explanation is that severe forms of SpA are more commonly observed in men, leading to a predominance of men in populations recruited from tertiary care units.

We also found a similar prevalence of $\mathrm{RA}^{18}$ and $\mathrm{SpA}$, whereas RA is usually reported as being more common. However, our results are in line with recent prevalence estimates conducted in more limited areas. One explanation is that inclusion of all the SpAs increases the prevalence in comparison with studies focusing on ankylosing spondylitis. Another explanation may be that the difference between RA and peripheral forms of SpA was recognised longer ago in France than in other countries, so that cases classified as RA elsewhere are classified as SpA in France. The use of the same population for studying RA and SpA prevalences should be considered, as RA predominates in women and the SpAs typically in younger men. Nevertheless, we elected to study the prevalence of both conditions in a random sample of adults, for three reasons: to obtain prevalence data in all age groups, to compare the prevalence of the two diseases in France, and to obtain information reflecting the overall public health impact of RA and SpA.

Although we found some heterogeneity across geographical regions of France, this was not statistically significant. The study may have lacked the statistical power needed to detect small differences across regions; it was powered to allow regional comparisons based on a 0.14 to 0.54 confidence interval.

Our study has a number of limitations. For ethical reasons, the questionnaire did not collect information on race or ethnicity. We did not ask rheumatologists to study HLA-B27 status, for two reasons: our clinical description of SpA was based on the ESSG criteria, which do not include HLA-B27, and French rheumatologists do not routinely test for HLAB27 when the diagnosis of SpA is established by other features, most notably sacroiliitis.

In conclusion, the prevalence of SpA in France was 0.30 in 2001 , with no differences between women $(0.29 \%$ (95\% CI 0.14 to 0.49$))$ and men $(0.31 \%(0.12$ to 0.60$))$. Ankylosing spondylitis and psoriatic arthritis are the most common subsets of SpA, but the interpenetration of various subsets warrants that all SpAs be pooled into a single group for epidemiological studies.

\section{ACKNOWLEDGEMENTS}

We thank the investigators and interviewers who contributed to this survey in Amiens: G Clavel, JC Crépin; Brest: V Devauchelle, S Jousse, Grenoble: Ph Gaudin, B Gintz, E Rolland; Nancy: V Capron, F Doriat, S Etienne, G Fenot, MC Gautier, N Jay, D Loeuille, C Michel, J Pourel; and Toulouse: F Navaud. 
We are grateful for the valuable contribution made by the following patient organisations: ACSAC, AFLAR, AFP, AFS, ANDAR, ARP, Fibromyalgies, PALMA.

This study received financial support from France-Telecom, and Institut CSA-TMO.

This survey was supported with an unconditional grant from Pharmacia, France, and a grant from the Société Française de Rhumatologie (French Society of Rheumatology).

\section{Authors' affiliations}

A Saraux, Rheumatology, University Hospital, Brest, France F Guillemin, E Le Bihan, EA 3444, School of Public Health, Nancy, France

P Guggenbuhl, Rheumatology, University Hospital, Rennes, France C H Roux, L Euller-Ziegler, Rheumatology, University Hospital, Nice, France

P Fardellone, Rheumatology, University Hospital, Amiens, France A Cantagrel, Rheumatology, University Hospital, Toulouse, France I Chary-Valckenaere, Rheumatology, University Hospital, Nancy,

France

R-M Flipo, Rheumatology, University Hospital, Lille, France

R Juvin, Rheumatology, University Hospital, Grenoble, France

J-M Behier, Pharmacia

B Fautrel, Rheumatology, Pitié-Salpêtrière University Hospital, Paris, France

C Masson, Rheumatology, University Hospital, Angers, France

J Coste, Biostatistics, Cochin University Hospital, Paris, France

Alain Saraux, Francis Guillemin, Pascal Guggenbuhl, Christian H Roux, Patrice Fardellone, Bruno Fautrel, Charles Masson, Joel Coste are members of the epidemiology section of the Société Française de Rhumatologie.

\section{REFERENCES}

1 European Spondylarthropathy Study Group. Preliminary criteria for the classification of spondylarthropathy. Arthritis Rheum 1991;34:1218-27.

2 Amor B, Dougados M, Miijiyawa M. Critères diagnostiques des spondylarthropathies. Rev Rhum 1990;57:85-9.

3 Boyer GS, Lanier AP, Templin W. Prevalence rates of spondyloarthropathies, rheumatoid arthritis and other rheumatic disorders in an Alaska Inupiat Eskimo population. J Rheumatol 1988;15:678-83.

4 Fender $P$, Paita M, Ganay D, Benech JM. Prévalence des 30 affections de longue durée pour les affiliés au régime général de l'assurance maladie en 1994. Rev Epidemiol Sante Publique 1997;45:454-64.

5 Steven MM. Prevalence of chronic arthritis in four geographical areas of the Scottish highlands. Ann Rheum Dis 1992;51:186-94.
6 Braun J, Bollow M, Remlinger G, Eggens U, Rudwaleit M, Distler A, et al. Prevalence of spondylarthropathies in HLA-B27 positive and negative blood donors. Arthritis Rheum 1998;41:58-67.

7 Lawrence RC, Helmick CG, Arnett FC, Deyo RA, Felson DT, Giannini EH, et al. Estimates of the prevalence of arthritis and selected musculoskeletal disorders in the United States. Arthritis Rheum 1998;41:778-9.

8 Wigley RD, Zhang NZ, Zeng QY, Shi CS, Hu DW, Couchman K, et al. Rheumatic diseases in China. J Rheumatol 1994;21:1484-90.

9 Adebajo AO, Davis P. Rheumatology on the dark continent. Not as dark as it was. J Rheumatol 1992;19:195-7.

10 Alamanos Y, Papadopoulos NG, Voulgari PV, Karakatsanis A, Siozos C, Drosos AA. Epidemiology of ankylosing spondylitis in Northwest Greece, 1983-2002. Rheumatology (Oxford) 2004;43:615-18.

11 Alamanos Y, Papadopoulos NG, Voulgari PV, Siozos C, Psychos DN Tympanidou $M$, et al. Epidemiology of psoriatic arthritis in northwest Greece, 1982-2001. J Rheumatol 2003;30:2641-4.

12 Hukuda S, Minami M, Saito T, Mitsui H, Matsui N, Komatsubara Y, et al. Prevalence of spondyloarthropathy in Japan. J Rheumatol 2002;29:1105-7.

13 Braun J, Bollow M, Remlinger G, Eggens U, Rudwaleit M, Distler A, et al. Prevalence of spondylarthropathies in HLA-B27 positive and negative blood donors. Arthritis Rheum 1998;41:58-67.

14 Saraux A, Guedes C, Allain J, Devauchelle V, Valls I, Lamour A, et al. Survey of rheumatoid arthritis and spondylarthropathy in Brittany. J Rheumatol 1999:26:2622-6.

15 Saraux A, Guillemin F, Saraux A, Fardellone P, Guggenbuhl P, Behier JM, et al. Agreement between rheumatologist visit and lay interviewer telephone survey for screening for rheumatoid arthritis and spondyloarthropathy. Joint Bone Spine 2004:71:44-50.

16 Guillemin F, Saraux A, Fardellone P, Guggenbuhl P, Behier JM, Coste J, et al. Detection of cases of inflammatory rheumatic disorders: performance of a telephone questionnaire designed for use by patient interviewers. Ann Rheum Dis 2003:62:957-63.

17 Salmon CT, Nichols JS. The next-birthday method of respondent selection. Public Opinion Quarterly 1983;47:270-6.

18 Guillemin F, Saraux A, Guggenbuhl P, Roux CR, Fardellone P, Le Bihan E, et al. Prevalence of rheumatoid arthritis in France: 2001. Ann Rheum Dis 2005;64:1427-30.

19 Marcus AC, Crane LA. Telephone surveys in public health research. Med Care 1986;24:97-112.

20 Siemiatycki J. A comparison of mail, telephone, home, and home interview strategies for household health surveys. Am J Public Health 1979;69:238-45.

21 Siemiatycki J, Campbell S. Nonresponse bias and early versus all responders in mail and telephone surveys. Am J Epidemiol 1984;120:291-300.

22 Aneshensel C, Frerichs R, Clarck V, Yokopenic P. Telephone versus in-person surveys of community health status. Am J Public Health 1982;72:1017-21.

23 Korner-Bitensky N, Wood-Dauphinee S, Siemiatycki J, Shapiro S. Healthrelated information postdischarge: telephone versus face-to-face interviewing Arch Phys Med Rehabil 1994;75:1287-96.

24 Haapanen N, Miilunpalo S, Pasanen M, Oja P, Vuori I. Agreement between questionnaire data and medical records of chronic diseases in middle-aged and elderly Finnish men and women. Am J Epidemiol 1997;145:762-9.

25 Barlow JH, Turner AP, Wright CC. Comparison of clinical and self-reported diagnoses for participants on a community-based arthritis self-management programme. Brit J Rheumatol 1998;36:985-7. 